\title{
Pulmonary carcinosarcoma showing an obvious response to pazopanib: a case report
}

\author{
Azusa Tanimoto ${ }^{1 *}$ (D), Shinji Takeuchi ${ }^{1}$, Hiroshi Kotani ${ }^{1}$, Kaname Yamashita', Tadaaki Yamada ${ }^{2}$, Koushiro Ohtsubo ${ }^{1}$ \\ Hiromichi Ebi', Hiroko Ikeda ${ }^{3}$ and Seiji Yano'
}

\begin{abstract}
Background: Pulmonary carcinosarcoma (PCS) is a rare primary lung malignancy and has a poor prognosis among lung tumor histological subtypes. However, an appropriate treatment strategy has not been developed for unresectable PCS.

Case presentation: A 65-year-old man who was diagnosed with PCS was treated by surgical removal of the primary lung lesion, followed by six cycles of adjuvant chemotherapy with cisplatin plus irinotecan. Following the chemotherapy, he experienced a relapse with brain metastasis, which induced the rapid onset of left leg paralysis. Radical surgical resection and stereotactic radiosurgery to the resection cavity were performed. However, meningeal dissemination and new lung metastases occurred after a year and half. To control these multiple metastatic lesions, the patient was treated with the multiple kinase inhibitor pazopanib. No change was observed in the meningeal dissemination, while the metastatic lung lesions were prominently reduced in size following treatment with pazopanib. Consequently, the patient showed a partial response to pazopanib treatment, although the dose of pazopanib was reduced by half as a result of thrombocytopenia.
\end{abstract}

Conclusion: This is the first report of metastatic PCS showing an evident therapeutic response to tumor-targeted therapy. We suggest that pazopanib may be a therapeutic option for patients with metastatic PCS.

Keywords: Pulmonary carcinosarcoma, Pazopanib, Thrombocytopenia, VEGFR

\section{Background}

Pulmonary carcinosarcoma (PCS), which accounts for only $0.3 \%$ of all lung tumors, is a rare histological subtype of non-small lung cancer (NSCLC) [1]. PCS is defined by the presence of epithelial elements (squamous or adenocarcinoma) combined with sarcomatous elements such as rhabdomyosarcoma, osteosarcoma, or chondrosarcoma [2]. A few studies have demonstrated the presence of common chromosomal abnormalities in the epithelial and sarcomatous components of PCS [3, 4], suggesting a monoclonal origin of PCS tumors. Standard therapy for PCS has not yet been established owing to the low incidence of this type of tumor. Pazopanib, a multi-targeted tyrosine kinase inhibitor against the proto-oncogene c-Kit (c-KIT), platelet-derived growth factor receptor (PDGFR), fibroblast growth factor receptor (FGFR), and vascular

\footnotetext{
* Correspondence: atanimoto@staff.kanazawa-u.ac.jp

'Division of Medical Oncology, Cancer Research Institute, Kanazawa

University, 13-1, Takara-machi, Kanazawa, Ishikawa 920-0934, Japan

Full list of author information is available at the end of the article
}

endothelial growth factor receptor (VEGFR), has been reported to show beneficial outcomes in patients with metastatic non-adipocytic soft-tissue sarcoma and renal cell carcinoma, and superior safety and quality-of-life profiles compared with sunitinib, which is a similar targeted drug $[5,6]$. Here, we report the first case of metastatic PCS that showed a remarkable response to pazopanib despite the necessity of dose reduction owing to thrombocytopenia.

\section{Case report}

A 65-year-old man who never smoked and had consulted a local hospital 3 years earlier presented to our hospital, where he was diagnosed with PCS and treated with right pneumonectomy, followed by six cycles of adjuvant chemotherapy with cisplatin plus irinotecan, because the pTNM stage was PT3N1M0 stage IIIA according to the 7 th lung cancer TNM classification. One year later, he experienced the rapid onset of left lower extremity paralysis, and brain gadolinium contrast-enhanced magnetic resonance imaging (MRI) performed in our hospital revealed a

(c) The Author(s). 2018 Open Access This article is distributed under the terms of the Creative Commons Attribution 4.0 International License (http://creativecommons.org/licenses/by/4.0/), which permits unrestricted use, distribution, and reproduction in any medium, provided you give appropriate credit to the original author(s) and the source, provide a link to the Creative Commons license, and indicate if changes were made. The Creative Commons Public Domain Dedication waiver (http://creativecommons.org/publicdomain/zero/1.0/) applies to the data made available in this article, unless otherwise stated. 


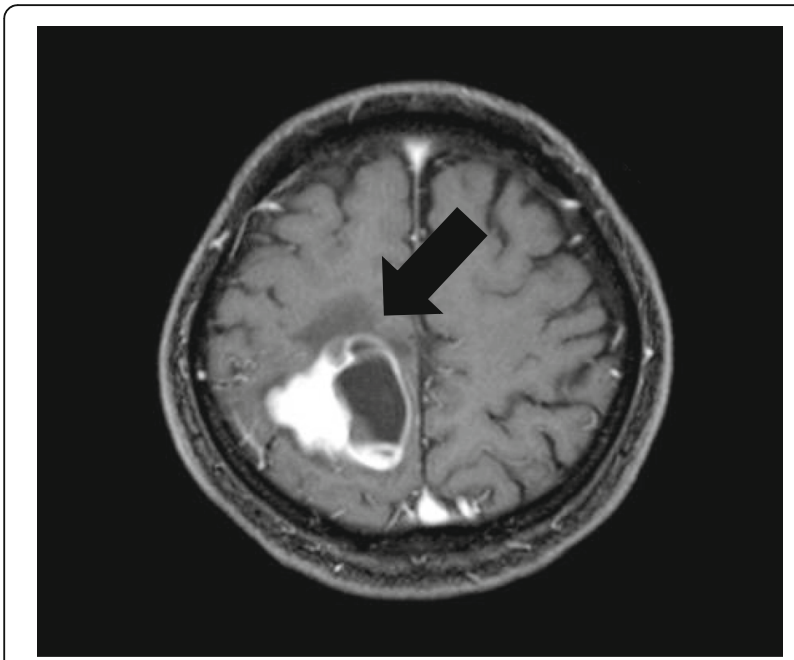

Fig. 1 Brain magnetic resonance imaging (MRI) reveals a cerebral ring-enhancing lesion with hemorrhage (arrow)

new brain mass with active bleeding in the right parietal lobe (Fig. 1). The patient was treated with surgical resection, followed by stereotactic radiosurgery to the resection cavity. Immunohistochemical analysis of resected tissue samples revealed sarcomatous tumors composed of spindle cells and cartilage and epithelial tumors expressing cytokeratin AE1/AE3 (Fig. 2a, b). These histological findings were quite similar to those observed with tissue from pneumonectomy specimens (Fig. 2c, d). Therefore, we made a definitive histological diagnosis of metastatic PCS on the brain tumor specimens. A year and a half after this operation, brain gadolinium contrast-enhanced MRI revealed meningeal dissemination (Fig. 3a), and chest radiography identified two nodules in the left lower lung field (Fig. 3b) which were diagnosed with lung recurrence although the lesions were not verified histologically for fear of fatal iatrogenic pneumothorax because of right pneumonectomy. The patient began treatment for PCS with pazopanib (Votrient ${ }^{\circ}$, GlaxoSmithKline, Uxbridge, Middlesex, UK) $800 \mathrm{mg}$ orally once a day on the basis of the histological diagnosis because pazopanib has been approved for the treatment of soft tissue sarcoma in Japan. Two weeks after treatment initiation, the patient was withdrawn from the drug because his platelet count was reduced to $60,000 / \mu \mathrm{L}$. Since the platelet count recovered to above the lower limit of normal 2 weeks later, he was permitted to resume pazopanib at $400 \mathrm{mg}$ orally once a day. Although a brain MRI scan showed no change in the meningeal dissemination, a chest and abdominal computed tomography scan demonstrated a reduction in size of $60 \%$ in the lung metastatic lesions of PCS according to Response Evaluation Criteria In Solid Tumors (RECIST) version 1.1 after 2 months of treatment (Fig. 4a-d). His quality of life during the pazopanib treatment had kept adequate because there was little adverse event by pazopanib except thrombocytopenia. 6 months later, the patient showed consciousness disorder due to the progression of the meningeal dissemination and stopped taking pazopanib despite the lung metastatic lesions kept shrinking.

\section{Discussion and conclusions}

Complete surgical resection is the first choice for standard treatment for PCS, if possible. On the other hand,

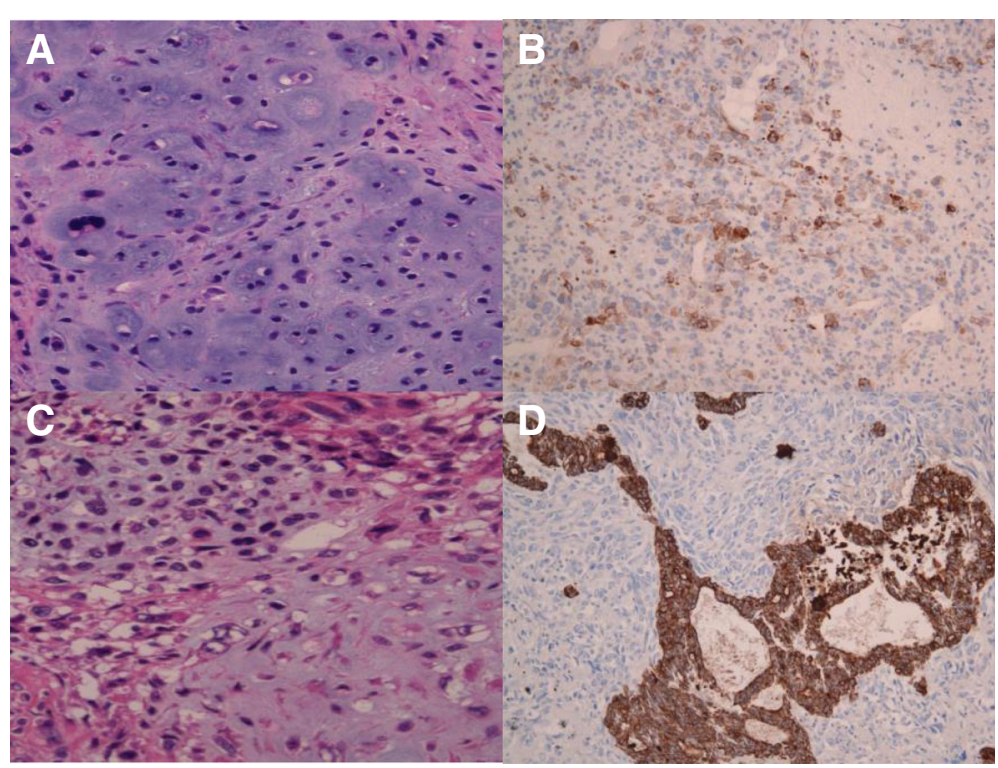

Fig. 2 Histological findings: Photomicrograph of resected specimen from brain metastases demonstrates cartilage compositions (a) (hematoxylin and eosin [HE] staining, $\times 100$ ) and epithelial tumors (b) (cytokeratin AE1/AE3 staining, $\times 100$ ). $\mathbf{c}$, d Photomicrograph of HE and cytokeratin AE1/AE3 stained specimen demonstrates findings conformable with resected specimen from primary lung lesion (magnification, $\times 100$ ) 


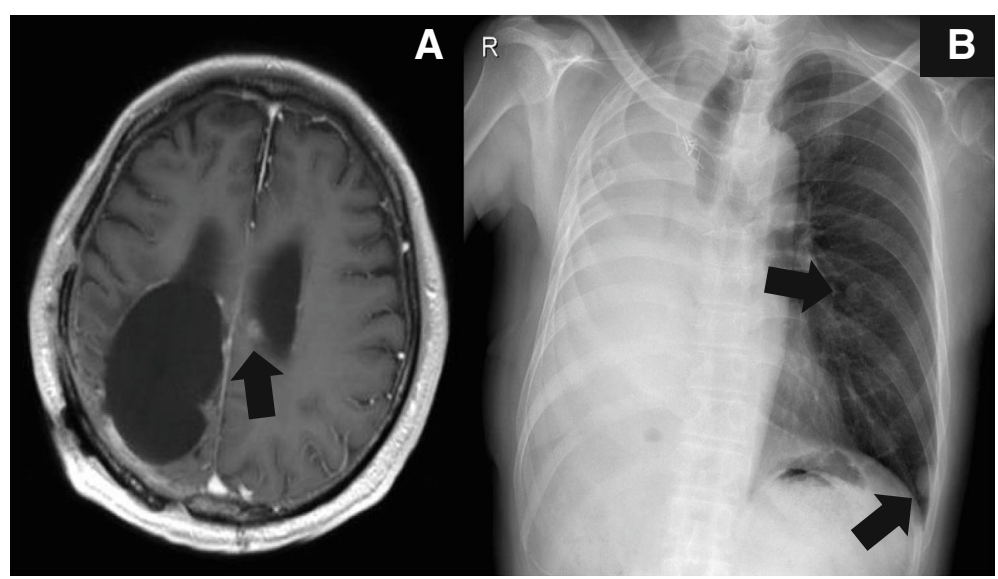

Fig. 3 a Brain magnetic resonance imaging (MRI) shows meningeal dissemination in left lateral ventricle (arrow). b Chest x-ray scan shows two nodule shadows in left lower lung field (arrow)

effective systemic chemotherapy in patients with inoperable PCS has not yet been developed [7] although the prognosis of PCS is poorer than that of other types of NSCLC [8]. In the present report, the multiple kinase inhibitor pazopanib showed an obvious effect in a case of metastatic PCS.

Several papers have reported that the prognosis of patients with PCS was poor, with a median survival of approximately 1 year $[9,10]$. Although a few reports showed that doxorubicin-based regimens had some effect on metastatic PCS $[1,11]$, standard chemotherapy for metastatic PCS has not yet been developed [12]. Therefore, pazopanib has the potential to become one of the new treatment options for inoperable PCS.

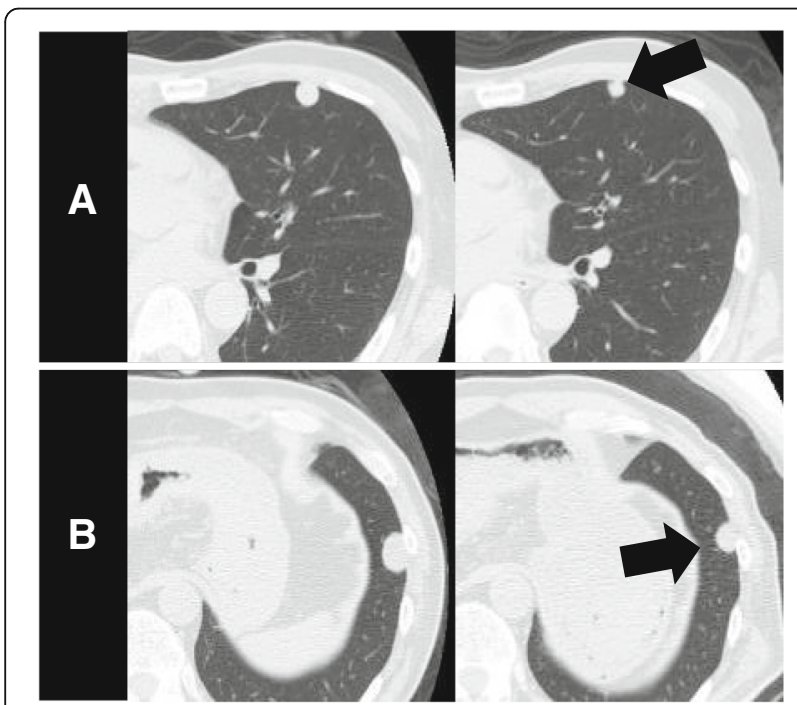

Fig. 4 Computed tomography $(\mathrm{CT})$ image illustrates two nodules in left upper lobe (a) and lower lobe (b) prior to treatment. The size of the nodules (arrow) was reduced following treatment (right panel)
In-frame deletions at exon 19 in the EGFR gene in both the carcinomatous component and the sarcomatous component have been detected in resected PCS specimens [13], indicating the potential to identify oncogenic driver mutations for targeting in PCS tumors. We performed mutational analysis of KIT Proto-Oncogene Receptor Tyrosine Kinase (KIT) and Platelet-Derived Growth Factor Receptor-A (PDGFRA) genes in the present case, because pazopanib has inhibitory activity on PDGFR- $\alpha / \beta$ and $c-K i t$ [14]. We found no active mutations of these genes, suggesting that the tumor regression in the present case might be attributable to inhibition by pazopanib of VEGFR instead of that of KIT and PDGFR. Previous research demonstrated that VEGF, but not c-KIT, epidermal growth factor receptor (EGFR), or human epidermal growth factor receptor 2 (HER-2), was strongly expressed in both the carcinomatous component and the sarcomatous component in 30 cases of uterine carcinosarcoma [15]. Clinical analysis revealed that increased VEGF and VEGFR-3 expression indicated poor survival in uterine and ovarian carcinosarcomas from analysis of 25 patient samples [16]. Therefore, it would be valuable if the expression of VEGF and VEGFR in PCS tumors could be surveyed, which could indicate the possibility of a novel treatment strategy via the VEGF/VEGFR axis in PCS. Further clinical study is needed to elucidate the crucial signals for PCS.

In the present case, the pulmonary metastatic lesions from PCS showed a marked reduction in size in response to pazopanib treatment. This is the first case of PCS demonstrating a good clinical response to molecular targeted therapy. Although a phase II clinical study found that the response rate to pazopanib in uterine carcinosarcoma was $0 \%(0 / 19)$ [17], another study reported the first cases of positive clinical response to pazopanib in patients with uterine carcinosarcoma and ovarian carcinosarcoma [18]. 
These findings would indicate the heterogeneity of dominant survival signals in carcinosarcoma regardless of the primary lesions. Therefore, the attempt should be made to identify a predictive biomarker, such as VEGF/VEGFR, for response to certain specific drugs in types of carcinosarcoma including PCS.

We have reported the case of a patient with PCS who showed a good response to pazopanib, albeit with dose reduction by half owing to adverse effects. Pazopanib may have potential in the treatment of PCS. Although PCS is extremely rare, continued study of the clinical benefits of pazopanib may aid in the development of a new therapeutic strategy for patients with metastatic PCS.

\section{Abbreviations}

c-KIT: Proto-oncogene c-Kit; PCS: Pulmonary carcinosarcoma; PDGFR: Plateletderived growth factor receptor; VEGFR: Vascular endothelial growth factor receptor

\section{Acknowledgements}

The authors wish to thank Mitsutoshi Nakada, Katsuyoshi Miyashita for operating the patient.

\section{Funding}

Not applicable.

\section{Availability of data and materials}

All data are presented in the manuscript.

\section{Authors' contributions}

AT and SY were involved with concept and design of this manuscript. AT, ST and SY were involved with making treatment decisions. AT and TY were involved with drafting this manuscript. $\mathrm{HK}, \mathrm{KY}, \mathrm{KO}, \mathrm{HE}$ and $\mathrm{HI}$ proofread the manuscript. All authors have read and approved the final version of the edited manuscript.

\section{Ethics approval and consent to participate}

Not applicable.

\section{Consent for publication}

Written informed consent was obtained from the patient for publication of this case report and any accompanying images. A copy of the written consent is available for review by the Editor of this journal.

\section{Competing interests}

The authors declare that they have no competing interests.

\section{Publisher's Note}

Springer Nature remains neutral with regard to jurisdictional claims in published maps and institutional affiliations.

\section{Author details}

'Division of Medical Oncology, Cancer Research Institute, Kanazawa University, 13-1, Takara-machi, Kanazawa, Ishikawa 920-0934, Japan. ${ }^{2}$ Department of Pulmonary Medicine, Graduate School of Medical Science, Kyoto Prefectural University of Medicine, Kyoto, Japan. ${ }^{3}$ Division of Pathology, Kanazawa University Hospital, Kanazawa, Japan.

Received: 16 November 2017 Accepted: 30 November 2018 Published online: 12 December 2018

\section{References}

1. Davis MP, Eagan RT, Weiland LH, Pairolero PC. Carcinosarcoma of the lung: Mayo Clinic experience and response to chemotherapy. Mayo Clin Proc. 1984;59:598-603

2. Koss MN, Hochholzer L, Frommelt RA. Carcinosarcomas of the lung: a clinicopathologic study of 66 patients. Am J Surg Pathol. 1999;23:1514-26.
3. Dacic S, Finkelstein SD, Sasatomi E, Swalsky PA, Yousem SA. Molecular pathogenesis of pulmonary carcinosarcoma as determined by microdissection-based allelotyping. Am J Surg Pathol. 2002;26:510-6.

4. Pardo J, Aisa G, de Alava E, Sola JJ, Panizo A, Rodriguez-Spiteri N, et al. Primary mixed squamous carcinoma and osteosarcoma (carcinosarcomas) of the lung have a CGH mapping similar to primitive squamous carcinomas and osteosarcomas. Diagnostic Mol Pathol B. 2008;17:151-8.

5. van der Graaf WT, Blay JY, Chawla SP, Kim DW, Bui-Nguyen B, Casali PG, et al. Pazopanib for metastatic soft-tissue sarcoma (PALETTE): a randomised, double-blind, placebo-controlled phase 3 trial. Lancet (London, England). 2012;379:1879-86.

6. Motzer R, Hutson TE, Cella D, Reeves J, Hawkins R, Guo J, et al. Pazopanib versus sunitinib in metastatic renal-cell carcinoma. N Engl J Med. 2013;369:722-31.

7. Pelosi G, Sonzogni A, De Pas T, Galetta D, Veronesi G, Spaggiari L, et al. Review article: pulmonary sarcomatoid carcinomas: a practical overview. Int J Surg Pathol. 2010;18:103-20.

8. Martin LW, Correa AM, Ordonez NG, Roth JA, Swisher SG, Vaporciyan AA, et al. Sarcomatoid carcinoma of the lung: a predictor of poor prognosis. Ann Thorac Surg. 2007;84:973-80.

9. Wick MR, Ritter JH, Humphrey PA. Sarcomatoid carcinomas of the lung: a clinicopathologic review. Am J Clin Pathol. 1997;108(1):40-53.

10. Weissferdt A, Moran CA. Malignant biphasic tumors of the lungs. Adv Anat Pathol. 2011;18:179-89.

11. Langer F, Wintzer HO, Werner M, Weber C, Brummendorf TH, Bokemeyer C. A case of pulmonary carcinosarcoma (squamous cell carcinoma and osteosarcoma) treated with cisplatin and doxorubicin. Anticancer Res. 2006:26:3893-7.

12. Huang SY, Shen SJ, Li XY. Pulmonary sarcomatoid carcinoma: a clinicopathologic study and prognostic analysis of 51 cases. World J Surg Oncol. 2013;11:252.

13. Toyokawa G, Takenoyama M, Taguchi K, Arakaki K, Inamasu E, Toyozawa R, et al. The first case of lung carcinosarcoma harboring in-frame deletions at exon19 in the EGFR gene. Lung Cancer (Amsterdam, Netherlands). 2013;81:491-4.

14. Sonpavde G, Hutson TE. Pazopanib: a novel multitargeted tyrosine kinase inhibitor. Curr Oncol Rep. 2007:9:115-9.

15. Cimbaluk D, Rotmensch J, Scudiere J, Gown A, Bitterman P. Uterine carcinosarcoma: immunohistochemical studies on tissue microarrays with focus on potential therapeutic targets. Gynecol Oncol. 2007;105:138-44.

16. Nayha V, Stenback F. Angiogenesis and expression of angiogenic agents in uterine and ovarian carcinosarcomas. APMIS. 2008:116:107-17.

17. Campos SM, Brady WE, Moxley KM, O'Cearbhaill RE, Lee PS, DiSilvestro PA, et al. A phase II evaluation of pazopanib in the treatment of recurrent or persistent carcinosarcoma of the uterus: a gynecologic oncology group study. Gynecol Oncol. 2014;133:537-41.

18. Nishikawa T, Hasegawa K, Yabuno A, Yoshida H, Yasuda M, Kozawa E, et al. Pazopanib as a second line treatment for uterine and ovarian carcinosarcoma: a single institutional study. J Gynecol Oncol. 2017;28:e25.

\section{Ready to submit your research? Choose BMC and benefit from:}

- fast, convenient online submission

- thorough peer review by experienced researchers in your field

- rapid publication on acceptance

- support for research data, including large and complex data types

- gold Open Access which fosters wider collaboration and increased citations

- maximum visibility for your research: over $100 \mathrm{M}$ website views per year

At $\mathrm{BMC}$, research is always in progress.

Learn more biomedcentral.com/submission 